\title{
¿Otra vez el Fascismo Eterno?
}

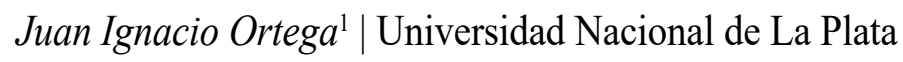

Revista Derechos en Acción ISSN 2525-1678/ e-ISSN 2525-1686

Año 4/NNo 10 Verano 2018/2019 (21 diciembre a 21 marzo), 451-458

DOl: https://doi.org/10.24215/25251678e264

El proyecto político del gobierno encabezado por Jair Bolsonaro reúne ciertos puntos de lo que Eco llama "Fascismo Eterno"2. Hablamos de esto debido a que, en su discurso, Bolsonaro presenta una retórica fuertemente xenófoba, racista, clasista, militarista y machista que no esconde y la utiliza como modo de ganar adeptos. Esta construcción discursiva fue decisiva para que los brasileros se vuelquen en las urnas a votarlo, agotados de un sistema político en decadencia desde el escándalo del Lava Jato $^{3}$ que provocó que el Brasil se inmiscuya en una crisis política, social y económica que tiene como hechos más relevantes el "Impeachment" a Dilma Rousseff el encarcelamiento de varios políticos por hechos de corrupción como el presidente de la Cámara de Diputados Eduardo Cunha $^{5}$ (impulsor del juicio político a Dilma) y el hecho más

1 Estudiante de la carrera de abogacía de la Facultad de Ciencias Jurídicas y Sociales de la UNLP.

2 ECO, Umberto (1997). "El fascismo eterno". En Cinco Escritos Morales (Cinque scritti morali), traducción de Helena Lozano Miralles. Sant Adrià de Besòs:Lumen. P 33-59.

3 La Operación Lava Jato es una investigación iniciada en 2014 por la Policía Federal Brasilera en la cual se descubre una supuesta red de lavado de dinero en la cual se verían implicados múltiples actores de la política brasilera. Para entender de qué se trata podemos leer Operação Lava Jato desarticula rede de lavagem de dinheiro em 7 estados en la Agencia de Noticias de la Policia Federal Brasilera. (consultado el 19 de noviembre de 2018)

4 Brasil: el Senado destituyó a Dilma Rousseff por amplia mayoría. La Nación (consultado el 19 de noviembre de 2018)

5 Antonio Jiménez Barca Detenido en Brasil Eduardo Cunha, impulsor del 'Impeachment' a Dilma Rousseff. Diario El País. (consultado el 19 de noviembre de 2018) 
importante: la persecución, detención y proscripción política a Lula Da Silva, candidato natural del Partido de los Trabajadores y claro líder en todas las encuestas electorales ${ }^{6}$.

A esta crisis de legitimidad del sistema político brasileño le tenemos que agregar la fuerte recesión económica acompañada de una reforma laboral que fue impulsada por el impopular expresidente Michel Temer. Los partidos políticos que dominaron la esfera política de Brasil los últimos tiempos, el Partido de la Socialdemocracia Brasilera (los "tucanos") y el Movimiento Democrático Brasilero han detonado su capital político (sus candidatos Gerardo Alckmin y Henrique Meirelles sacaron 5\% y $1 \%$, en las elecciones); las cámaras se encuentran completamente balcanizadas ${ }^{7}$ y el dominio de la llamada "Bancada BBB" representante de la oligarquía terrateniente, la industria armamentística y los evangelistas es casi absoluto ${ }^{8}$.

Antonio Gramsci definía las crisis como "El viejo mundo se muere y lo nuevo no puede nacer: en este interregno se verifican los fenómenos morbosos más variados" ese monstruo es Bolsonaro al que se lo puede definir como un fascista (lo expondré a continuación) o (como el que escribe suscribe) un pinochetista debido a su visión militarista, represiva y neoliberal, hijo de las dictaduras promovidas por Estados Unidos en Latinoamérica para instaurar un modelo económico de exclusión de matriz neoliberal en la región y disciplinar la oposición política a este modelo.

\footnotetext{
6 Santiago Aristia Brasil: según encuestas, Lula da Silva es el favorito para las presidenciales pese a estar en prisión. France24 (consultado el 19 de noviembre de 2018)

7 La Cámara de Diputados está compuesta por 513 diputados y el bloque con más miembros es el del Partido Social Liberal con solo 55 diputados mientras que en el Senado Federal de 81 senadores el bloque con más miembros es el del Movimiento Democrático Brasilero con solo 13 escaños.

8 Con la composición actual de la Cámara de Diputados la Bancada BBB posee 223 miembros. Para conocer más puede leer: Rafael Tatemoto Bancada BBB se reconfigura e pode ampliar influencia nos próximos quatro anos en Brasil de Fato (consultado el 15 de febrero de 2019).

9 GRAMSCI, Antonio (1930). En Cuadernos de la Cárcel. Cita en el Tomo dos, cuaderno tres, página 37 \& apartado 34 in fine, traducción de Ana María Palos. Editorial ERA (1981).
} 
Bolsonaro, siguiendo las enumeraciones que hace Eco se lo puede considerar un fascista a pesar de no cumplir con todos conceptos señalados ${ }^{10}$.

En primer lugar, Eco habla de un "culto de la tradición" en el Ur-fascismo que en el electo presidente del Brasil podemos notar indefectiblemente, ya que uno de los pilares de campaña principales de Bolsonaro estuvo centrado en la defensa de "los valores de la tradición judeocristiana" en contrapartida de la "ideología de género" 11 . Utilizando todos los medios a su alcance, Bolsonaro logró instalarse como el principal defensor de los valores de vida brasileros contra "el Comunismo". El lema de la campaña electoral "Brasil encima de todo, Dios encima de todos" es el ejemplo más claro de ese tradicionalismo arraigado fuertemente a la religiosidad de Brasil y el recelo de la mayoría de la población contra el matrimonio homosexual y la comunidad LGBT.

Lo que define Eco en el culto de la acción por la acción cuando dice: "El mayor empeño de los intelectuales fascistas oficiales consistía en acusar a la cultura moderna y a la intelligentsia liberal de haber abandonado los valores tradicionales"12. Se ve también en Bolsonaro, crítico fervoroso de Paulo Freire ${ }^{13}$ al que tomó como adversario preferido y a sus ideas como enemiga a abatir, a las que considera marxistas, a tal punto de decir que quería "entrar al Ministerio de Educación con un lanzallamas

\footnotetext{
10 Las características típicas pueden resumirse según Eco en: culto a la tradición, rechazo del modernismo, culto de la acción por la acción, rechazo del pensamiento crítico ("el desacuerdo es traición", p. 51, ibíd.); miedo a la diferencia, Ilamamiento a las clases medias frustradas, obsesión por el complot (xenofobia); rechazo al pacifismo ("vida para la lucha"); elitismo y "rechazo a los débiles", educación para el heroísmo y culto a la muerte; machismo (transferencia de la voluntad de poder a cuestiones sexuales, p. 54, ibíd.); Populismo cualitativo; uso de la "neolengua".

11 “Vamos a unir al pueblo, valorizar la familia, respetar las religiones y nuestras tradiciones judeocristianas, combatir la ideología de género conservando nuestros valores. Brasil volverá a ser un país libre de las amarras ideológicas" Sostuvo Bolsonaro en su discurso de investidura, reafirmando su matriz en la estructura discursiva que utilizó durante la campaña electoral.

12 Eco, ibíd. P. 50

13 Educador y alfabetizador popular brasileño, autor entre otras obras fundamentales de La educación como práctica de la libertad y Pedagogía del oprimido.
} 
para eliminar a Paulo Freire" De ahí también surge algo llamativo en sus seguidores que tienen una facilidad increíble en llamar comunista a cualquiera que se le ocurra criticarlo, los fanáticos llegaron a denominar como comunista a Francis Fukuyama por escribir algo en contra de Bolsonaro en su Twitter personal.

Para el fascismo el desacuerdo es traición según Eco, y no hay nada más visible en Bolsonaro. Previo al ballotage el candidato proponía, textualmente, "limpiar Brasil de marginales rojos" donde los enmarca como enemigos de la nación y amenaza con encarcelarlos o matarlos. Con eso Bolsonaro toma al pueblo de Brasil como un actor uniforme y que no tendrá disidencias con su proyecto político y al que lo esté será castigado. Es el factor que más lo expone ya que, en el nazismo y en el fascismo italiano, se trató de totalizar al pueblo en uno, que seguía los mandatos del líder sin cuestionar y que lo aclamaba y defendían su accionar y al que se oponía se lo mataba o se lo enviaba a un campo de concentración. Siguiendo ese aspecto totalizador de la masa y en consonancia con el desacuerdo, Eco señala que el fascismo le teme a la diversidad y para explicitarlo nada mejor que escuchar un discurso de Bolsonaro en el cual les dice a las minorías que si no quieren desaparecer deben adecuarse a las mayorías.

Eco señala también que el fascismo es machista y quien hay como Bolsonaro para demostrar lo que dice: el notable desprecio contra las mujeres es muy común en sus presencias y no le interesa velarlo en lo más mínimo. Desde decir que sus hijos eran una bendición excepto su hija que fue un error de Dios, de gritarle a una diputada del $\mathrm{PT}^{14}$ que no la violaría por ser fea, de decir que hay algunas mujeres que pueden ganar lo mismo que un varón son demasiadas las exposiciones públicas donde Bolsonaro muestra su machismo y lo defiende, a lo

14 "Graba esto aquí, me está llamando violador. Jamás la violaría, ya que usted no lo merece" Bolsonaro a Maria do Rosário Nunes, diputada federal por el PT en el año 2003. Ya en el 2014, el actual presidente lejos de arrepentirse sostendría que "no merecería ser violada, porque es muy mala, muy fea" en referencia a la misma mujer. 
que sumamos su homofobia y su absoluto desprecio y racismo sobre la población negra.

Pero para mí, la clave del fenómeno Bolsonaro es algo que Eco señala al decir que:

El Ur-Fascismo surge de la frustración individual o social. Lo cual explica por qué una de las características típicas de los fascismos históricos ha sido el llamamiento a las clases medias frustradas, desazonadas por alguna crisis económica o humillación política, asustadas por la presión de los grupos sociales subalternos ${ }^{15}$.

En esta cita se explica lo que sucedió en Brasil, una sociedad que vio estos últimos años como toda su clase política se veía salpicada por escándalos de corrupción y como esta iba entrando en un estado de disgregación. Como expliqué al principio, el impeachment a Dilma y la detención de principales empresarios del país y lo explícito de la corrupción (videos de cómo Temer pedía recibir coimas, por ejemplo) sumándole una crisis económica y las constantes medidas de ajuste de la economía desde la presidencia de Rousseff fueron creando un escenario político ideal para la aparición de un líder "anti-establishment" que concentrase toda esa "bronca" popular. Ese líder parecía ser Lula, pero con su proscripción y la lógica de "Lula me cuidaba, ahora el ya no está y Bolsonaro me va a dar un arma para que me cuide" Bolsonaro pasó a ser la esperanza de esa clase media y baja levantando un discurso muy duro contra la corrupción y contra el sistema político brasilero que cautivó a mucha gente que sentía no encontrar ese líder protector que no podía ser Lula (aunque se debe aclarar que gran parte del voto de Bolsonaro es de un raigambre anti PT temeroso del comunismo).

De ese Brasil surgió este líder político al que le podemos encontrar muchas similitudes con el Fascismo Eterno de Eco, pero se le encuentran diferencias con lo que es el viejo fascismo

15 Eco, ibíd. p. 50, el subrayado es del original. 
ya que no tiene pretensiones imperialistas, por ejemplo. Eso sí, es un hijo directo de las dictaduras latinoamericanas con su exacerbado militarismo y un programa económico ultra neoliberal comandado por un Chicago Boy como es Paulo Guedes ${ }^{16}$.

Ya en la presidencia Bolsonaro está expuesto a diversos desafíos a los que se expuso debido a su retórica histriónica que lo ayudó a conseguir apoyos de amplios sectores sociales. El voto a Bolsonaro está compuesto en su mayoría por los trabajadores del sector industrial paulista, la clase media de las grandes ciudades blancas y donde predomina el evangelismo de Brasil (Rio de Janeiro, Curitiba, Porto Alegre, Belo Horizonte y la mencionada San Pablo) mientras que en el nordeste brasilero pobre, negro y católico el PT sostuvo su capital electoral. ${ }^{17}$ La clave del triunfo de Bolsonaro no solo estuvo en los sectores anteriormente nombrados sino que logró penetrar en sectores de clase baja que antes se volcaban a otras ofertas. La promesa de mayor seguridad y la creación de una atmósfera por parte de Bolsonaro como defensor de los valores tradicionales del Brasil hicieron que el cordero vote al lobo.

Al llegar al poder el primer decreto de Bolsonaro consistió en una rebaja del salario mínimo ${ }^{18}$ con lo que se confirma lo mencionado por el que escribe sobre la presencia de elementos que nos recuerdan al gobierno de Augusto Pinochet en Chile en el cual el neoliberalismo y el alineamiento a la política exterior de Estados Unidos, velado por un discurso y una acción reaccionaria, son sus características más notorias.

A su vez, Bolsonaro está en constante disputa interna con el Ejército de Brasil, que fue una de sus fuentes principales de apoyo. Con el Vicepresidente Hamilton Mourão a la cabeza, el

\footnotetext{
16 Actual Ministro de Economía de Brasil, egresado en la Universidad Federal de Minas Gerais. En 1974 ingresó al Departamento de Economía de la Universidad de Chicago, cuna del neoliberalismo.

17 El País Bolsonaro arrasa en ciudades blancas y ricas: un mapa del voto en 5500 municipios

18 El Cronista Bolsonaro debutó con una rebaja del salario mínimo previsto para 2019 (consultado el 15 de febrero)
} 
Ejército presiona a Bolsonaro pidiéndole más presencia en el gobierno (actualmente cuenta con ocho ministros) ${ }^{19}$ con el fin de tener más autonomía y disminuir la influencia del ministro más importante, Guedes "marcándole la cancha" al presidente y su programa político. Es menester recordar que el Ejército de Brasil cuando tuvo el poder en su país (la dictadura que transcurrió durante veintiún años entre 1964 y 1985) no suscribió a las políticas neoliberales del momento sino que mantuvo un plan desarrollista donde el sector industrial paulista (el ABC) tuvo un papel central. Estos desmarques del Ejército con la política del gobierno son comunes y uno de los últimos ejemplos es el rechazo a una intervención militar de Estados Unidos en Venezuela y la apertura del diálogo entre generales de las Fuerza Armada Nacional Bolivariana y los del Ejército Brasilero ${ }^{20}$.

Las dificultades que Bolsonaro está teniendo para cumplir sus promesas electorales no significan que no haya tomado medidas simbólicas para mostrar a sus votantes como por ejemplo la exclusión del organigrama del Ministerio de la Mujer, la Familia y los Derechos Humanos (a cargo de la pastora evangélica Damares Alves) la protección de los derechos humanos de la comunidad $\mathrm{LGBT}^{21}$, la quita de la protección a los territorios indígenas $^{22}$ y las declaraciones de la anteriormente nombrada ministra Alves donde celebra que en el nuevo Brasil las niñas vestirán de rosa y los niños de azul ${ }^{23}$.

La presidencia del Bolsonaro recién tiene pocos meses, notaremos en el transcurso del tiempo los alcances de su política,

\footnotetext{
19 Ámbito Partido Militar: ya son ocho los ministros con uniforme. (consultado el 20 de febrero)

20 Infobae, El Vicepresidente de Brasil dijo que una acción militar de Estados Unidos en Venezuela no tendría sentido (consultado el 22 de febrero)

21 HOY de Córdoba Bolsonaro sacó de la órbita estatal a la comunidad LGBT (consultado el 20 de febrero)

22 New York Times En su primer día, Jair Bolsonaro socavó los derechos de los indígenas sobre su tierras (consultado el 20 de febrero)

23 “¡Atención, atención! Es una nueva era en Brasil: niño viste de azul y niña viste de rosa" se le escuchó decir en un video a la ministra Damares Alves
} 
sus limitaciones, sus acciones y si consolida su poder dentro de la estructura que actualmente lo está solventando al mando de la principal economía de América del Sur. Hasta ahora, se presenta un camino espinoso para el ex capitán del Ejército y del lema electoral "Brasil encima de todo y Dios encima de todos" queda un Bolsonaro sometido a la benevolencia de Dios que tendrá que lidiar con su propia base de apoyos y su capacidad de cumplir con las promesas a cada uno de los grupos que lo llevaron al Palacio do Planalto para que el Brasil no se lo lleve puesto a él. 